\title{
Effects of Molecular Weight of Reaction Media on Formation of Volatile Oligomers by Thermal Degradation of Polyisobutylene $e^{\dagger, \dagger}$
}

\author{
Takashi SAWAGUCHI* and Manabu SENO \\ Department of Industrial Chemistry, College of Science and Technology, Nihon University, \\ Kandasurugadai, Chiyoda-ku, Tokyo 101, Japan
}

(Received August 10, 1995)

\begin{abstract}
For the thermal degradation of polyisobutylene, the effects of physical factors such as pressure in the reaction vessel and volume and molecular weight of the molten polymer matrix constituting the reaction media on the formation of the volatile oligomers were examined by a kinetic approach with measurements of composition ratios for terminal monoolefins $\left[(T T D)_{p},(T V D)_{p},(T T D)_{t}\right.$, and $\left.\left.(T V D)_{t}\right)\right]$. The observed values of the composition ratios $[T T D]_{p} /[T V D]_{p}$ and $[T T D]_{t} /[T V D]_{t}$ are kept constant independently of changes in the physical factors. On the other hand, the ratios $[T T D]_{p} /[T T D]_{t}$ and $[T V D]_{\mathrm{p}} /[T V D]_{\mathrm{t}}$ do not depend on pressure and initial mass of sample, but depend on the initial molecular weight of sample. These values decrease clearly as the initial molecular weight decreases. It could be deduced that the decrease in molecular weight of the matrix decreases concentration ratio of two types of terminal macroradicals $\left(\left[\mathbf{R}_{\mathrm{p}} \cdot\right] /\left[\mathbf{R}_{\mathbf{t}} \cdot\right]\right)$. According to the proposed kinetics of a chain mechanism including diffusion-controlled termination, a marked decrement of the radical concentration ratio suggests that the rate of termination increases with decrease in molecular weight of the matrix and that resulting decrement of kinetic chain length depresses the formation of the primary terminal macroradical $\left(R_{p} \cdot\right)$ in the depropagation step.
\end{abstract}

KEY WORDS Thermal Degradation / Polyisobutylene / Volatile Oligomer / Kinetics / Intramolecular Hydrogen Abstraction / Back-Biting / Diffusion-Controlled Termination / Molecular Weight Dependence / Chain Length Dependence /

Although some physical factors such as volume and molecular weight of molten polymers as a reaction media affect polymer reactions in the melt, ${ }^{1 \mathrm{a}}$ there is little information regarding this problem. We examined this effects from detailed structural and kinetic analyses of the products in a series of studies on the thermal degradation of polyisobutylene. One of the most remarkable features of the thermal degradation of mainchain-scission type of polymers such as polyisobutylene, polyethylene, polypropylene, polystyrene, and poly(methyl methacrylate) is decrease in volume and molecular weight of the molten polymer matrix constituting the reaction media during degradation. In the previous papers, ${ }^{2}$ we showed that the main products in the volatile oligomers formed by thermal degradation of polyisobutylene are four types of terminal monoolefins, ${ }^{2 a}$ as shown below: a terminal vinylidene double bond (TVD) type and a terminal trisubstituted double bond (TTD) type of olefins with a tert-butyl end $(t-\mathrm{Bu})$ formed from a primary $(\mathrm{p})$ terminal macroradical $\left(\mathrm{R}_{\mathrm{p}} \cdot\right)$, and TVD and TTD type of olefins with an isopropyl end (i-Pr) formed from a tertiary $(\mathrm{t})$ terminal macroradical $\left.\left(\mathrm{R}_{\mathrm{t}} \cdot\right)\right)$;

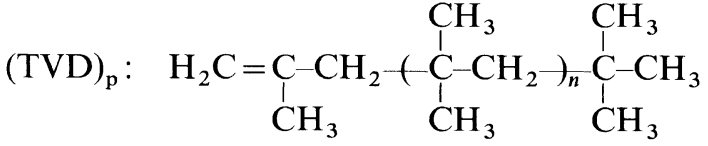

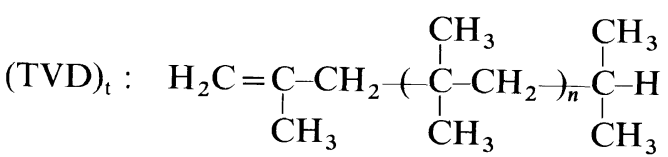

\footnotetext{
+ Thermal Degradation of Polymers in the Melt III.

${ }^{\dagger+}$ For Part II, see ref 2 b.

* To whom correspondence should be addressed.
}<smiles>CC(C)=CC(C)(C)CCC(C)(C)CCC(C)(C)C(C)=CC(C)(C)C</smiles>

Each homologue consists of oligomers from dimers to dodecamers. The formation of these olefins could be reasonably explained by the reaction model consisting of the intramolecular hydrogen abstraction (back-biting) of $\mathrm{R}_{\mathrm{p}} \cdot$ and $\mathrm{R}_{\mathrm{t}} \cdot$ and the subsequent $\beta$ scission at the inner position of the main chain. ${ }^{3}$ The reactivities for abstraction of interest hydrogens $\left(\mathrm{CH}_{2}\right.$ and $\left.\mathrm{CH}_{3}\right)$ are governed not by the steric hindrance-depending mechanism ${ }^{1 \mathrm{~b}, 3}$ but by the bond energy-depending mechanism. The latter mechanism predicts that back-biting occurs predominantly at $\mathrm{CH}_{2}$ rather than at $\mathrm{CH}_{3}$ in the same manner as intermolecular hydrogen abstractions ${ }^{4}$ of both $R_{p}$. and $R_{t} \cdot$, in conformity with the order of bond dissociation energies of respective $\mathrm{H}-\mathrm{C}$ bonds. This prediction is supported by the results of kinetic analysis on the back-bitings based on the composition ratios $[T T D]_{\mathrm{p}} /[\mathrm{TVD}]_{\mathrm{p}}$ and $[\mathrm{TTD}]_{\mathrm{t}} /[\mathrm{TVD}]_{\mathrm{t}} \cdot{ }^{2 \mathrm{~b}}$ Moreover, this results suggest that the back-biting depends only on the molecular conformation of the reacting chain ends. On the other hand, the results of the ratios $[T T D]_{\mathrm{p}} /[\mathrm{TTD}]_{\mathrm{t}}$ and $[\mathrm{TVD}]_{\mathrm{p}} /[\mathrm{TVD}]_{\mathrm{t}}$ suggest that the terminal macroradical concentration ratio $\left(\left[\mathrm{R}_{\mathrm{p}} \cdot\right] /\left[\mathrm{R}_{\mathrm{t}} \cdot\right]\right)$ decreases owing to changes in the physical factors of reaction media during the degradation. ${ }^{2 \mathrm{~b}}$

In this paper, the effects of the physical factors such as pressure in the reaction vessel and the volume and molecular weight of the molten polymer matrix on the 
thermal degradation of polyisobutylene are examined and a degradation mechanism including diffusioncontrolled termination is proposed.

\section{EXPERIMENTAL}

\section{Sample, Apparatus, and Procedure}

Polyisobutylene used was a commercial "Vistanex L" manufactured by EXXON CHEMICAL Co., Ltd. and purified by dissolving in chloroform in an $\mathrm{N}_{2}$ stream and precipitating with acetone. The precipitates were washed with methanol several times, and then used as an original sample after vacuum drying under heating. Six polyisobutylene samples having different molecular weights were prepared from the polymer residue obtained by thermal degradation of the original polyisobutylene and these samples should have terminal double bonds (TVD and TTD). ${ }^{4}$ One of these samples was hydrogenated. Their characteristics are given in Table I.

The experimental procedure for thermal degradation is described in preceding papers. ${ }^{2}$ During the thermal degradation, the reacting molten polymer in the reaction vessel was vigorously stirred with bubbles of $\mathrm{N}_{2}$ introduced under reduced pressure. The standard reaction conditions are as follows: sample weight, $1 \mathrm{~g}$; pressure, 3-4 mmHg. A mercury-diffusion pump was used at the pressure below $1 \mathrm{mmHg}$. After the reaction, the volatile oligomers were recovered into a liquid fraction trap chilled with liquid $\mathrm{N}_{2}$ and dissolved in acetone for analysis. The polymer residue in the reaction vessel was dissolved in chloroform and reprecipitated with acetone to remove small amounts of the semi-volatile oligomers. These reprecipitates were termed nonvolatile oligomers and their molecular weights were determined after vacuum drying under heating. The volatilization which represents the rate of formation of volatiles was obtained from the following equation: $100 \times($ weight of sample weight of polymer residues)/(weight of sample).

\section{Analysis}

The analytical GC of the volatile oligomers was recorded on a Shimadzu GC-8A gas chromatograph equipped with a flame-ionization detector and a fused silica capillary column $(50 \mathrm{~m} \times 0.35 \mathrm{~mm}$ i.d. $)$ consisting of the OV-1 liquid phase. Measurement conditions are

Table I. Characteristics of polyisobutylene samples having different molecular weights

\begin{tabular}{cc}
\hline$M_{n 0} \times 10^{-3 \mathrm{a}}$ & $\frac{\bar{M}_{\mathrm{w}}^{\mathrm{b}}}{\bar{M}_{\mathrm{n}}}$ \\
\hline 250 & 2.50 \\
$64.8^{\mathrm{c}}$ & 2.43 \\
$49.9^{\mathrm{c}}$ & 2.35 \\
$7.09^{\mathrm{c}}$ & 1.64 \\
$7.09^{\mathrm{d}}$ & 1.82 \\
$3.62^{\mathrm{c}}$ & 1.35 \\
$2.30^{\mathrm{c}}$ & 1.36 \\
$2.00^{\mathrm{c}}$ & 1.28
\end{tabular}

${ }^{a}$ By limiting viscosity number measurements. ${ }^{\mathrm{b}}$ By GPC measurements. ${ }^{c}$ Oligomer sample before hydrogenation prepared by thermal degradation of the PIB $\left(M_{n 0}=2.50 \times 10^{5}\right)$. ${ }^{\mathrm{d}}$ Oligomer sample after hydrogenation of the thermally prepared oligomer $\left(M_{n 0}=7.09 \times 10^{3}\right)$. described elsewhere. ${ }^{2 b}$ The composition ratio for each oligomer is the relative ratio of peak intensity, measured with a digital integrator without calibration.

The number average molecular weight $\left(M_{n}\right)$ of the nonvolatile oligomers was calculated by the following equation ${ }^{5}$ using the limiting viscosity number measured at $30^{\circ} \mathrm{C}$ in toluene: $[\eta]=3.71 \times 10^{-4} \mathrm{P}^{0.75}$, where $[\eta]$ is the limiting viscosity number $\left(\mathrm{Lg}^{-1}\right)$ and $\mathrm{P}$ is the number average degree of polymerization determined by the osmotic pressure method.

Molecular weight distribution $\left(M_{w} / M_{n}\right)$ of the nonvolatile oligomers were measured by GPC (Toyo Soda HLC-802 UR). The data were calibrated by the standard, polystyrene.

\section{Hydrogenation of the Nonvolatile Oligomers}

The procedure for hydrogenation is described in a preceding paper. ${ }^{2}$ In the case of the nonvolatile oligomers, the reaction mixture was filtered and dropped into acetone. The precipitate was used as a hydrogenated sample after vacuum drying under heating.

\section{RESULTS AND DISCUSSION}

Figure 1 illustrates the time courses of volatilization and $M_{n}$ of the nonvolatile oligomers formed during the degradation of polyisobutylene $\left(M_{n 0}=2.50 \times 10^{5}\right){ }^{2}$ The increase in volatilization and decrease in $M_{n}$ during degradation mean decrement of volume and molecular weight of the molten polymer matrix.

\section{Kinetic Expression of Composition Ratio}

In a preceding paper, ${ }^{2 \mathrm{~b}}$ we derived eq 1 to 4 for the composition ratios for monoolefins from kinetic analysis, assuming that the back-biting competitively occurs under a steady state regarding on-chain macroradicals.

$$
\begin{aligned}
& \frac{[\mathrm{TTD}]_{\mathrm{p}}}{[\mathrm{TVD}]_{\mathrm{p}}}=\frac{k_{\mathrm{pb} 2}\left[\mathbf{R}_{\mathrm{p}} \cdot\right]}{k_{\mathrm{pb} 1}\left[\mathbf{R}_{\mathrm{p}} \cdot\right]}=\frac{k_{\mathrm{pb} 2}}{k_{\mathrm{pb} 1}} \\
& \frac{[\mathrm{TTD}]_{\mathrm{t}}}{[\mathrm{TVD}]_{\mathrm{t}}}=\frac{k_{\mathrm{tb} 2}\left[\mathbf{R}_{\mathrm{t}} \cdot\right]}{k_{\mathrm{tb} 1}\left[\mathbf{R}_{\mathrm{t}} \cdot\right]}=\frac{k_{\mathrm{tb} 2}}{k_{\mathrm{tb} 1}} \\
& \frac{[\mathrm{TVD}]_{\mathrm{p}}}{[\mathrm{TVD}]_{\mathrm{t}}}=\frac{k_{\mathrm{pb} 1}\left[\mathbf{R}_{\mathrm{p}} \cdot\right]}{k_{\mathrm{tb} 1}\left[\mathbf{R}_{\mathrm{t}} \cdot\right]}
\end{aligned}
$$

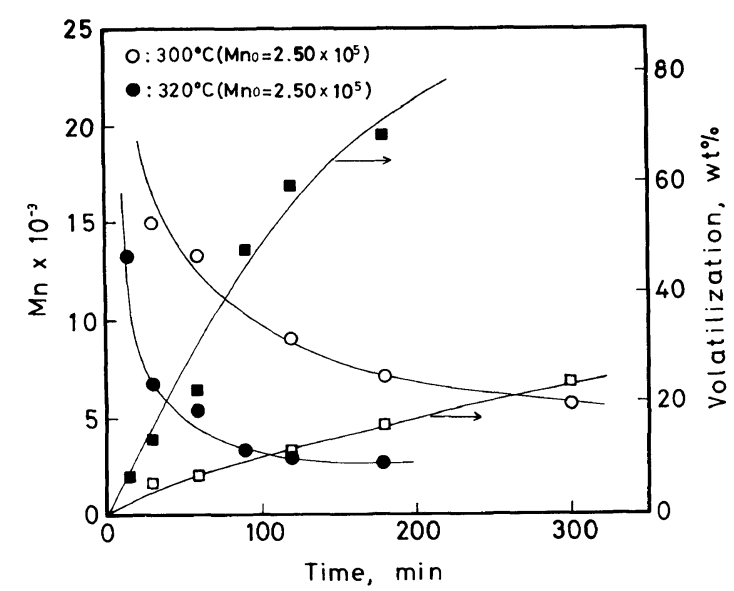

Figure 1. Time course of the volatilization and $M_{n}$ of the nonvolatile oligomers during the degradation of polyisobutylene $\left(M_{n 0}=\right.$ $\left.2.50 \times 10^{5}\right) .^{2 b}$ 


$$
\frac{[\mathrm{TTD}]_{\mathrm{p}}}{[\mathrm{TTD}]_{\mathrm{t}}}=\frac{k_{\mathrm{pb} 2}\left[\mathbf{R}_{\mathrm{p}} \cdot\right]}{k_{\mathrm{tb} 2}\left[\mathbf{R}_{\mathrm{t}} \cdot\right]}
$$

where,

$$
\left[\mathbf{R}_{\mathrm{p}} \cdot\right]=\int\left[\mathrm{R}_{\mathrm{p}} \cdot\right] \mathrm{d} t \text { and }\left[\mathbf{R}_{\mathrm{t}} \cdot\right]=\int\left[\mathrm{R}_{\mathrm{t}} \cdot\right] \mathrm{d} t
$$

The ratios $[\text { TTD }]_{\mathrm{p}} /[\text { TVD }]_{\mathrm{p}}$ and $[\text { TTD }]_{\mathrm{t}} /[\text { TVD }]_{\mathrm{t}}$ given by eq 1 and 2 correspond to those for abstraction rates of different types of hydrogens $\left(\mathrm{CH}_{2}\right.$ and $\left.\mathrm{CH}_{3}\right)$ of the same type of macroradicals. These values were observed to remain constant during the degradation and this verifies the validity of the kinetics. ${ }^{2 b}$ On the other hand, the ratios $[\text { TTD }]_{\mathrm{p}} /[\mathrm{TTD}]_{\mathrm{t}}$ and $[\text { TVD }]_{\mathrm{p}} /[\mathrm{TVD}]_{\mathrm{t}}$, defined by eq 3 and 4 , correspond to those for abstraction rates of the same type of hydrogens $\left(\mathrm{CH}_{2}\right.$ or $\left.\mathrm{CH}_{3}\right)$ of the different macroradicals, decrease markedly ${ }^{2 b}$ and this means a decrease in the radical concentration ratio. These results would be affected by changes in the volume ${ }^{6}$ and molecular weight of the reaction matrix. ${ }^{1 \mathrm{~b}, 2 \mathrm{~b}}$ The volatile oligomers are formed in the molten polymer phase and transferred by heating from the polymer phase to gaseous phase accompanied by $\mathrm{N}_{2}$ gas introduced into the polymer phase. In this investigation, the effects of pressure, volume and molecular weight on the composition ratios are examined by comparing the composition ratios for the respective monoolefins ranging from dimers to heptamers, determined by capillary GC.

\section{Effect of Pressure}

The original polyisobutylene was degraded during
$45 \mathrm{~min}$ under pressure from 0.1 to $168 \mathrm{mmHg}$ at $320^{\circ} \mathrm{C}$. The results are shown in Table II. Although $M_{n}$ of the nonvolatile oligomers scarcely changes with increasing pressure, the volatilization decreases. Any marked difference is not found among the values of the composition ratios, but a slight change is detected at $95 \mathrm{mmHg}$ and above. Some secondary reactions of the volatile oligomers having higher molecular weights seem to take place under higher pressures. This suggests that the secondary reactions of the volatile oligomers up to dodecamers could be neglected at the standard pressure of 4 $\mathrm{mmHg}$ in this experiment.

\section{Effects of Volume}

The volume of molten polymer matrix constituting the reaction media decreases as degradation proceeds (Figure 1). There is the possibility that a change in volume affects the degradation reaction through a temperature gradient in the molten polymer owing to heat and diffusional transfer of the volatile oligomers formed. ${ }^{6}$ If degradation is affected by the volume, the observed values of the composition ratios should vary with change in volume. The effect of volume was examined by varying the initial sample weight from 0.4 to $1 \mathrm{~g}$. The results are given in Table III. At both temperatures $\left(300\right.$ and $\left.320^{\circ} \mathrm{C}\right)$, volatilization, $M_{n}$, of the nonvolatile oligomers and composition ratios of oligomers are not affected by the initial sample weight. This shows that such a change in the volume of reaction media hardly influences the formation or secondary reactions of the volatile oligomers. Because the reacting

Table II. Changes in the composition ratios for all oligomers in the volatile oligomers by thermal degradation of polyisobutylene $\left(M_{\mathrm{n} 0}=2.50 \times 10^{5}\right)$ under various pressures

\begin{tabular}{|c|c|c|c|c|c|c|c|c|c|c|c|c|}
\hline \multirow{3}{*}{$\frac{\text { Temp }}{{ }^{\circ} \mathrm{C}}$} & \multirow{3}{*}{$\frac{\text { Time }}{\min }$} & \multirow{3}{*}{$\begin{array}{c}\text { Pressure } \\
\mathrm{mmHg}\end{array}$} & \multirow{3}{*}{$M_{n} \times 10^{-3 \mathrm{a}}$} & \multirow{3}{*}{$\begin{array}{c}\text { Volatil- } \\
\text { ization } \\
\text { wt } \%\end{array}$} & \multicolumn{4}{|c|}{ Trimers $(n=1)$} & \multicolumn{4}{|c|}{ Tetramers $(n=2)$} \\
\hline & & & & & \multirow{2}{*}{$\frac{[\mathrm{TTD}]_{\mathrm{p}}}{[\mathrm{TVD}]_{\mathrm{p}}}$} & \multirow{2}{*}{$\frac{[\mathrm{TTD}]_{\mathrm{t}}}{[\mathrm{TVD}]_{\mathrm{t}}}$} & \multirow{2}{*}{$\begin{array}{c}{[\mathrm{TVD}]_{\mathrm{p}}} \\
{[\mathrm{TVD}]_{\mathrm{t}}}\end{array}$} & \multirow{2}{*}{$\frac{[\mathrm{TTD}]_{\mathrm{p}}}{[\mathrm{TTD}]_{\mathrm{t}}}$} & \multirow{2}{*}{$\begin{array}{l}\overline{[\mathrm{TTD}]_{\mathrm{p}}} \\
{[\mathrm{TVD}]_{\mathrm{p}}}\end{array}$} & \multirow{2}{*}{$\begin{array}{c}{[\mathrm{TTD}]_{\mathrm{t}}} \\
{[\mathrm{TVD}]_{\mathrm{t}}}\end{array}$} & \multirow{2}{*}{$\begin{array}{l}{[\mathrm{TVD}]_{\mathrm{p}}} \\
{[\mathrm{TVD}]_{\mathrm{t}}}\end{array}$} & \multirow{2}{*}{$\frac{[\mathrm{TTD}]_{\mathrm{p}}}{[\mathrm{TTD}]_{\mathrm{t}}}$} \\
\hline & & & & & & & & & & & & \\
\hline \multirow[t]{8}{*}{320} & 45 & 0.09 & 4.08 & 24.6 & 2.41 & 1.05 & 9.87 & 22.7 & 1.92 & 1.46 & 5.55 & 7.32 \\
\hline & 45 & 0.10 & 3.80 & 29.1 & 2.40 & 1.15 & 8.73 & 18.3 & 1.85 & 1.41 & 4.83 & 6.33 \\
\hline & 45 & 0.44 & 4.81 & 18.4 & 2.36 & 1.12 & 11.5 & 24.2 & 1.86 & 1.41 & 6.42 & 8.46 \\
\hline & 45 & 0.65 & 4.62 & 21.0 & 2.43 & 1.15 & 9.81 & 20.8 & 1.87 & 1.47 & 5.92 & 7.52 \\
\hline & 45 & 4 & 4.32 & 27.2 & 2.49 & 1.19 & 10.7 & 22.3 & 1.97 & 1.47 & 5.48 & 7.34 \\
\hline & 45 & 36 & 5.02 & 18.9 & 2.70 & 1.25 & 10.7 & 23.0 & 1.74 & 1.21 & 5.47 & 7.90 \\
\hline & 45 & 95 & 4.65 & 18.8 & 2.33 & 0.97 & 11.8 & 28.4 & 1.79 & 1.27 & 5.07 & 7.11 \\
\hline & 45 & 168 & 5.20 & 13.4 & 2.06 & 0.90 & 15.3 & 35.1 & 1.65 & 1.34 & 5.75 & 7.07 \\
\hline
\end{tabular}

(Part 1)

\begin{tabular}{|c|c|c|c|c|c|c|c|c|c|c|c|c|}
\hline \multirow{3}{*}{$\frac{\text { Temp }}{{ }^{\circ} \mathrm{C}}$} & \multicolumn{4}{|c|}{ Pentamers $(n=3)$} & \multicolumn{4}{|c|}{ Hexamers $(n=4)$} & \multicolumn{4}{|c|}{ Heptamers $(n=5)$} \\
\hline & {$[\text { TTD }]_{p}$} & {$[\mathrm{TTD}]_{\mathrm{t}}$} & {$[\text { TVD }]_{\mathrm{p}}$} & {$[\text { TTD }]_{p}$} & {$[\mathrm{TTD}]_{\mathrm{p}}$} & {$\left[\mathrm{TTD}_{\mathrm{t}}\right.$} & {$[\text { TVD }]_{\mathrm{p}}$} & {$[\text { TTD }]_{p}$} & {$[\mathrm{TTD}]_{\mathrm{p}}$} & {$[\mathrm{TTD}]_{\mathrm{t}}$} & {$[\mathrm{TVD}]_{\mathrm{p}}$} & {$[\mathrm{TTD}]_{\mathrm{p}}$} \\
\hline & {$[\mathrm{TVD}]_{\mathrm{p}}$} & {$\left[\mathrm{TVD}_{\mathrm{t}}\right.$} & {$\left[\mathrm{TVD}_{\mathrm{t}}\right.$} & {$[\mathrm{TTD}]_{\mathrm{t}}$} & {$[\text { TVD }]_{\mathrm{p}}$} & {$\left[\mathrm{TVD}_{\mathrm{t}}\right.$} & {$\left[\mathrm{TVD}_{\mathrm{t}}\right.$} & {$[\mathrm{TTD}]_{\mathrm{t}}$} & {$[\mathrm{TVD}]_{\mathrm{p}}$} & {$\left[\mathrm{TVD}_{\mathrm{t}}\right.$} & {$\left[\mathrm{TVD}_{\mathrm{t}}\right.$} & {$[\mathrm{TTD}]_{\mathrm{t}}$} \\
\hline \multirow[t]{8}{*}{320} & 2.23 & 1.40 & 4.13 & 6.57 & 2.26 & 1.51 & 4.05 & 6.08 & 2.14 & 1.20 & 3.15 & 5.61 \\
\hline & 2.07 & 1.30 & 3.77 & 6.00 & 2.26 & 1.53 & 3.31 & 4.88 & 2.12 & 1.31 & 2.50 & 4.04 \\
\hline & 2.12 & 1.37 & 4.77 & 7.39 & 2.18 & 1.38 & 4.18 & 6.63 & 1.87 & 1.19 & 3.63 & 5.72 \\
\hline & 2.01 & 1.31 & 4.76 & 7.29 & 2.22 & 1.42 & 3.70 & 5.78 & 2.17 & 1.42 & 3.20 & 4.91 \\
\hline & 2.34 & 1.39 & 3.95 & 6.64 & 2.35 & 1.36 & 3.17 & 5.48 & 2.19 & 1.46 & 3.55 & 5.32 \\
\hline & 2.22 & 1.38 & 3.63 & 5.83 & 2.23 & 1.23 & 3.57 & 6.48 & 2.22 & 1.28 & 2.86 & 4.93 \\
\hline & 2.34 & 1.49 & 4.18 & 6.58 & 2.57 & 1.56 & 3.72 & 6.15 & 3.27 & 1.43 & 1.81 & 4.15 \\
\hline & 2.26 & 1.55 & 4.54 & 6.63 & 2.70 & 1.65 & 3.75 & 6.14 & 3.22 & 1.18 & 1.40 & 3.85 \\
\hline
\end{tabular}

(Part 2)

a By limiting viscosity number measurements. 
Table III. Changes in the composition ratios for all oligomers in the volatile oligomers by thermal degradation of polyisobutylene $\left(M_{n 0}=2.50 \times 10^{5}\right)$ with different initial sample weights

(Part 1)

\begin{tabular}{|c|c|c|c|c|c|c|c|c|c|c|c|c|}
\hline \multirow{3}{*}{$\frac{\text { Temp }}{{ }^{\circ} \mathrm{C}}$} & \multirow{3}{*}{$\frac{\text { Time }}{\min }$} & \multirow{3}{*}{$\begin{array}{c}\begin{array}{c}\text { Sample } \\
\text { weight }\end{array} \\
\mathrm{g}\end{array}$} & \multirow{3}{*}{$M_{n} \times 10^{-3 \mathrm{a}}$} & \multirow{3}{*}{$\begin{array}{c}\begin{array}{c}\text { Volatil- } \\
\text { ization }\end{array} \\
w t \%\end{array}$} & \multicolumn{4}{|c|}{ Trimers $(n=1)$} & \multicolumn{4}{|c|}{ Tetramers $(n=2)$} \\
\hline & & & & & {$[\mathrm{TTD}]_{\mathrm{p}}$} & {$[\mathrm{TTD}]_{\mathrm{t}}$} & {$[\mathrm{TVD}]_{\mathrm{p}}$} & {$[\mathrm{TTD}]_{\mathrm{p}}$} & {$\left[\mathrm{TTD}_{\mathrm{p}}\right.$} & {$[\mathrm{TTD}]_{\mathrm{t}}$} & {$[\mathrm{TVD}]_{\mathrm{p}}$} & {$[\mathrm{TTD}]_{\mathrm{p}}$} \\
\hline & & & & & {$[\text { TVD }]_{\mathrm{p}}$} & {$[\mathrm{TVD}]_{\mathrm{t}}$} & {$[\mathrm{TVD}]_{\mathrm{t}}$} & {$[\mathrm{TTD}]_{\mathrm{t}}$} & {$[\mathrm{TVD}]_{\mathrm{p}}$} & {$[\mathrm{TVD}]_{\mathrm{t}}$} & {$[\mathrm{TVD}]_{\mathrm{t}}$} & {$\left[\mathrm{TTD}_{\mathrm{t}}\right.$} \\
\hline \multirow[t]{4}{*}{300} & 120 & 1.0 & 7.82 & 10.3 & 2.13 & 1.17 & 15.7 & 28.7 & 1.62 & 1.37 & 9.37 & 11.0 \\
\hline & 120 & 0.8 & 7.82 & 12.0 & 1.81 & 1.22 & 18.6 & 27.7 & 1.67 & 1.45 & 7.83 & 9.05 \\
\hline & 120 & 0.6 & 7.06 & 10.4 & 2.16 & 1.17 & 15.1 & 27.7 & 1.91 & 1.50 & 8.33 & 10.6 \\
\hline & 120 & 0.4 & 6.66 & 10.6 & 2.27 & 1.32 & 15.0 & 25.7 & 2.07 & 1.56 & 7.09 & 9.42 \\
\hline \multirow[t]{4}{*}{320} & 45 & 1.0 & 4.32 & 27.2 & 2.49 & 1.19 & 10.7 & 22.3 & 1.97 & 1.47 & 5.48 & 7.34 \\
\hline & 45 & 0.8 & 5.00 & 23.6 & 2.48 & 1.19 & 12.0 & 25.0 & 1.98 & 1.51 & 5.92 & 7.76 \\
\hline & 45 & 0.6 & 4.70 & 30.7 & 2.38 & 1.10 & 9.74 & 21.0 & 1.88 & 1.41 & 5.00 & 6.65 \\
\hline & 45 & 0.4 & 4.80 & 24.9 & 2.54 & 1.21 & 9.78 & 20.6 & 1.88 & 1.48 & 5.80 & 7.34 \\
\hline \multicolumn{13}{|c|}{ (Part 2) } \\
\hline \multirow{2}{*}{ Temp } & \multicolumn{4}{|c|}{ Pentamers $(n=3)$} & \multicolumn{4}{|c|}{ Hexamers $(n=4)$} & \multicolumn{4}{|c|}{ Heptamers $(n=5)$} \\
\hline & {$[\mathrm{TTD}]_{\mathrm{p}}$} & {$[\mathrm{TTD}]_{\mathrm{t}}$} & {$[\text { TVD }]_{\mathrm{p}}$} & {$[\mathrm{TTD}]_{\mathrm{p}}$} & {$[\mathrm{TTD}]_{\mathrm{p}}$} & {$[\mathrm{TTD}]_{\mathrm{t}}$} & {$[\text { TVD }]_{p}$} & {$[\mathrm{TTD}]_{\mathrm{p}}$} & {$[\mathrm{TTD}]_{\mathrm{p}}$} & {$[\mathrm{TTD}]_{\mathrm{t}}$} & {$[\mathrm{TVD}]_{\mathrm{p}}$} & {$\left[\mathrm{TTD}_{\mathrm{p}}\right.$} \\
\hline${ }^{\circ} \mathrm{C}$ & {$[\mathrm{TVD}]_{\mathrm{p}}$} & {$[\mathrm{TVD}]_{\mathrm{t}}$} & {$[\mathrm{TVD}]_{\mathrm{t}}$} & {$[\mathrm{TTD}]_{\mathrm{t}}$} & {$[\mathrm{TVD}]_{\mathrm{p}}$} & {$\left[\mathrm{TVD}_{\mathrm{t}}\right.$} & {$[\mathrm{TVD}]_{\mathrm{t}}$} & {$[\mathrm{TTD}]_{\mathrm{t}}$} & {$[\mathrm{TVD}]_{\mathrm{p}}$} & {$[\mathrm{TVD}]_{\mathrm{t}}$} & {$[\mathrm{TVD}]_{\mathrm{t}}$} & {$[\mathrm{TTD}]_{\mathrm{t}}$} \\
\hline \multirow[t]{4}{*}{300} & 2.03 & 1.45 & 6.64 & 9.25 & 2.14 & 1.16 & 4.82 & 8.86 & 2.13 & 1.27 & 4.42 & 7.44 \\
\hline & 2.07 & 1.60 & 6.21 & 8.03 & 2.20 & 1.46 & 6.28 & 9.45 & 2.31 & 1.31 & 4.42 & 7.80 \\
\hline & 2.06 & 1.50 & 6.25 & 8.58 & 2.11 & 1.13 & 4.99 & 9.36 & 2.14 & 1.08 & 3.83 & 7.57 \\
\hline & 2.17 & 1.44 & 6.03 & 9.08 & 2.09 & 1.25 & 5.08 & 8.46 & 2.07 & 1.18 & 4.48 & 7.83 \\
\hline \multirow[t]{4}{*}{320} & 2.34 & 1.39 & 3.95 & 6.64 & 2.35 & 1.36 & 3.17 & 5.48 & 2.19 & 1.46 & 3.55 & 5.32 \\
\hline & 2.24 & 1.37 & 4.35 & 7.09 & 2.31 & 1.37 & 3.62 & 6.12 & 2.28 & 1.21 & 2.94 & 5.57 \\
\hline & 2.13 & 1.35 & 3.60 & 5.66 & 2.32 & 1.40 & 2.97 & 4.90 & 2.08 & 1.19 & 2.63 & 4.60 \\
\hline & 2.23 & 1.42 & 4.44 & 6.95 & 2.36 & 1.46 & 4.03 & 6.50 & 2.31 & 1.38 & 3.36 & 5.65 \\
\hline
\end{tabular}

${ }^{a}$ By limiting viscosity number measurements.

molten polymer in the reaction vessel is vigorously stirred with bubbles of $\mathrm{N}_{2}$ introduced, the molten polymer is mechanically well dispersed in the vessel during degradation. This would be one main reason why the change in volume scarcely influences degradation.

\section{Effects of Molecular Weight}

The effects of $M_{n}$ on the degradation were examined on the samples (Table I) prepared by thermal degradation. Table IV shows the results obtained for the degradation of seven samples of polyisobutylene at 300 and $320^{\circ} \mathrm{C}$. Volatilization increases with decrease in the initial molecular weight of samples, probably owing to increase in the rate of end initiation, as described in a later section.

Figures 2 and 3 show plots of $M_{n}$ of the nonvolatile oligomers $v s$. composition ratios for trimers with various initial molecular weights and reaction times. ${ }^{2 b}$ The relationships between the ratios and $M_{n}$ for various initial molecular weights are roughly consistent with those observed for change with reaction time. The relationships for tetramers to heptamers are similar to those for trimers. The ratios $[\text { TTD }]_{\mathrm{p}} /[\mathrm{TVD}]_{\mathrm{p}}$ and $[\mathrm{TTD}]_{\mathrm{t}} /$ $[\mathrm{TVD}]_{\mathrm{t}}$ remain constant, independently of the initial molecular weight (Table IV and Figure 2). Evidently, the fact that the rate constant ratios of eq 1 and 2 are kept constant during degradation confirms the validity of the assumption of the present kinetic analysis, that back-biting is of a uni-molecular type and its rate depends only on the local motion of the reacting end, independently of the chain length of the matrix and or reacting molecule itself. This suggests that back-biting is useful as a probe for analyzing the local motion of polymer molecules in the molten state.

The ratios $[\text { TTD }]_{\mathrm{p}} /[\mathrm{TTD}]_{\mathrm{t}}$ and $[\mathrm{TVD}]_{\mathrm{p}} /[\mathrm{TVD}]_{\mathrm{t}}$ decrease clearly as the initial molecular weight decreases, in spite of increment of $R_{p} \cdot$ as described above. The results (Table IV and Figure 3) show evidently that a marked decrement of the ratio $\left[\mathrm{R}_{\mathrm{p}} \cdot\right] /\left[\mathrm{R}_{\mathrm{t}} \cdot\right]$ with an increasing reaction time $\mathrm{e}^{2 \mathrm{~b}}$ results from decrease in molecular weight of reaction media.

\section{Molecular Weight Dependence}

The molecular weight dependence of the terminal macroradical concentration ratio $\left(\left[\mathbf{R}_{\mathrm{p}} \cdot\right] /\left[\mathbf{R}_{\mathrm{t}} \cdot\right]\right)$ can be estimated from eq 3 and 4 and the molecular weight of matrix (cf. Figure 3) and is given as follows,

$$
\begin{gathered}
\frac{\left[\mathbf{R}_{\mathrm{p}} \cdot\right]}{\left[\mathbf{R}_{\mathrm{t}} \cdot\right]} \propto \frac{[\mathrm{TVD}]_{\mathrm{p}}}{[\mathrm{TVD}]_{\mathrm{t}}} \propto \frac{[\mathrm{TTD}]_{\mathrm{p}}}{[\mathrm{TTD}]_{\mathrm{t}}} \propto M_{n}^{a} \\
\left(\frac{\left[\mathbf{R}_{\mathrm{p}} \cdot\right]}{\left[\mathbf{R}_{\mathrm{t}} \cdot\right]}\right)^{2} \propto\left(\frac{[\mathrm{TVD}]_{\mathrm{p}}}{[\mathrm{TVD}]_{\mathrm{t}}}\right)^{2} \propto\left(\frac{[\mathrm{TTD}]_{\mathrm{p}}}{[\mathrm{TTD}]_{\mathrm{t}}}\right)^{2} \propto M_{n}^{2 a}
\end{gathered}
$$

The double logarithmic plots of eq 6 were checked by the least square method, and the values of $2 a$ obtained with respect to the reaction time $\mathrm{e}^{2 \mathrm{~b}}$ are shown in Table V. At both 300 and $320^{\circ} \mathrm{C}$, the relationship given by eq 6 is verified with relatively high correlation for every oligomers. The observed value of exponent $2 a$ is around 
T. SaWAGUChi and M. SENo

Table IV. Changes in the comosition ratios for all oligomers of interest in the volatile oligomers by thermal degradation of polyisobutylenes with different initial molecular weights

(Part 1)

\begin{tabular}{|c|c|c|c|c|c|c|c|c|c|c|c|c|}
\hline \multirow{3}{*}{$\frac{\text { Temp }}{{ }^{\circ} \mathrm{C}}$} & \multirow{3}{*}{$\frac{\text { Time }}{\min }$} & \multirow{3}{*}{$M_{n 0} \times 10^{-3 \mathrm{a}}$} & \multirow{3}{*}{$M_{n} \times 10^{-3 \mathrm{a}}$} & \multirow{3}{*}{$\begin{array}{c}\begin{array}{c}\text { Volatil- } \\
\text { ization }\end{array} \\
\text { wt } \%\end{array}$} & \multicolumn{4}{|c|}{ Trimers $(n=1)$} & \multicolumn{4}{|c|}{ Tetramers $(n=2)$} \\
\hline & & & & & {$[\text { TTD }]_{\mathrm{p}}$} & {$[\mathrm{TTD}]_{\mathrm{t}}$} & {$[\text { TVD }]_{\mathrm{p}}$} & {$[\text { TTD }]_{p}$} & {$[\text { TTD }]_{\mathrm{p}}$} & {$\left[\mathrm{TTD}_{\mathrm{t}}\right.$} & {$\left[\mathrm{TVD}_{\mathrm{p}}\right.$} & {$[\text { TTD }]_{p}$} \\
\hline & & & & & {$[\mathrm{TVD}]_{\mathrm{p}}$} & {$[\mathrm{TVD}]_{\mathrm{t}}$} & {$[\mathrm{TVD}]_{\mathrm{t}}$} & {$[\mathrm{TTD}]_{\mathrm{t}}$} & {$[\text { TVD }]_{\mathrm{p}}$} & {$[\text { TVD }]_{\mathrm{t}}$} & {$[\mathrm{TVD}]_{\mathrm{t}}$} & {$\left[\mathrm{TTD}_{\mathrm{t}}\right.$} \\
\hline \multirow[t]{7}{*}{300} & 90 & 250 & 9.45 & 8.7 & 2.13 & 1.16 & 24.2 & 44.2 & 1.96 & 1.51 & 9.35 & 12.2 \\
\hline & 90 & $64.8^{\mathrm{b}}$ & 10.1 & 6.2 & 2.23 & 1.21 & 25.7 & 47.4 & 1.95 & 1.46 & 8.63 & 11.5 \\
\hline & 90 & $49.9^{\mathrm{b}}$ & 8.48 & 9.3 & 2.09 & 1.20 & 19.8 & 34.5 & 1.95 & 1.54 & 6.43 & 8.16 \\
\hline & 90 & $7.09^{b}$ & 3.68 & 22.1 & 2.14 & 1.09 & 6.80 & 13.4 & 1.91 & 1.45 & 3.50 & 4.61 \\
\hline & 90 & $7.09^{c}$ & 4.27 & 12.5 & 2.24 & 1.17 & 7.41 & 14.2 & 1.81 & 1.42 & 4.04 & 5.17 \\
\hline & 90 & $3.62^{\mathrm{b}}$ & 3.03 & 32.8 & 2.18 & 1.02 & 4.70 & 10.0 & 1.90 & 1.48 & 2.59 & 3.32 \\
\hline & 90 & $2.30^{\mathrm{b}}$ & 1.93 & 38.7 & 2.08 & 0.91 & 2.23 & 5.13 & 1.80 & 1.29 & 1.39 & 1.94 \\
\hline \multirow[t]{6}{*}{320} & 45 & 250 & 5.25 & 21.5 & 2.28 & 1.15 & 11.9 & 23.6 & 1.92 & 1.43 & 5.24 & 7.00 \\
\hline & 45 & $64.8^{\mathrm{b}}$ & 4.48 & 19.6 & 2.26 & 1.18 & 10.0 & 19.1 & 1.83 & 1.36 & 4.80 & 6.48 \\
\hline & 45 & $49.9^{b}$ & 4.02 & 23.1 & 2.25 & 1.17 & 8.56 & 16.5 & 1.79 & 1.31 & 4.22 & 5.78 \\
\hline & 45 & $7.09^{b}$ & 2.92 & 31.0 & 2.23 & 1.10 & 5.80 & 11.8 & 1.79 & 1.32 & 2.93 & 3.97 \\
\hline & 45 & $3.62^{\mathrm{b}}$ & 2.17 & 42.4 & 2.23 & 1.13 & 4.38 & 8.65 & 1.74 & 1.42 & 2.36 & 2.88 \\
\hline & 45 & $2.00^{\mathrm{b}}$ & 1.93 & 40.7 & 2.19 & 1.02 & 2.37 & 5.10 & 1.74 & 1.53 & 1.65 & 1.88 \\
\hline
\end{tabular}

(Part 2)

\begin{tabular}{|c|c|c|c|c|c|c|c|c|c|c|c|c|}
\hline \multirow{3}{*}{$\frac{\text { Temp }}{{ }^{\circ} \mathrm{C}}$} & \multicolumn{4}{|c|}{ Pentamers $(n=3)$} & \multicolumn{4}{|c|}{ Hexamers $(n=4)$} & \multicolumn{4}{|c|}{ Heptamers $(n=5)$} \\
\hline & {$[\mathrm{TTD}]_{\mathrm{p}}$} & {$[\text { TTD }]_{\mathrm{t}}$} & {$[\mathrm{TVD}]_{\mathrm{p}}$} & {$[\text { TTD }]_{p}$} & {$\left[\mathrm{TTD}_{\mathrm{p}}\right.$} & {$\left[\mathrm{TTD}_{\mathrm{t}}\right.$} & {$[\text { TVD }]_{p}$} & {$[\mathrm{TTD}]_{\mathrm{p}}$} & {$[\mathrm{TTD}]_{\mathrm{p}}$} & {$\left[\mathrm{TTD}_{\mathrm{t}}\right.$} & {$[\text { TVD }]_{p}$} & {$[\mathrm{TTD}]_{\mathrm{p}}$} \\
\hline & {$[\mathrm{TVD}]_{\mathrm{p}}$} & {$\left[\mathrm{TVD}_{\mathrm{t}}\right.$} & {$[\mathrm{TVD}]_{\mathrm{t}}$} & {$[\mathrm{TTD}]_{\mathrm{t}}$} & {$[\mathrm{TVD}]_{\mathrm{p}}$} & {$\left[\mathrm{TVD}_{\mathrm{t}}\right.$} & {$[\mathrm{TVD}]_{\mathrm{t}}$} & {$[\mathrm{TTD}]_{\mathrm{t}}$} & {$[\mathrm{TVD}]_{\mathrm{p}}$} & {$\left[\mathrm{TVD}_{\mathrm{t}}\right.$} & {$[\mathrm{TVD}]_{\mathrm{t}}$} & {$[\mathrm{TTD}]_{\mathrm{t}}$} \\
\hline \multirow[t]{7}{*}{300} & 2.08 & 1.34 & 6.05 & 9.38 & 2.11 & 1.06 & 4.40 & 8.76 & 2.10 & 1.23 & 4.70 & 7.99 \\
\hline & 2.11 & 1.45 & 4.67 & 6.80 & 2.13 & 1.22 & 4.13 & 7.21 & 2.13 & 1.27 & 4.03 & 6.80 \\
\hline & 2.00 & 1.35 & 4.58 & 6.75 & 2.16 & 1.25 & 3.75 & 6.45 & 2.14 & 1.34 & 3.83 & 6.13 \\
\hline & 2.27 & 1.60 & 2.76 & 3.91 & 2.31 & 1.28 & 2.17 & 3.71 & 2.17 & 1.35 & 2.13 & 3.42 \\
\hline & 2.18 & 1.63 & 3.00 & 4.01 & 2.11 & 1.30 & 2.66 & 4.32 & 2.05 & 1.45 & 2.84 & 4.00 \\
\hline & 2.15 & 1.53 & 2.08 & 2.92 & 2.05 & 1.41 & 1.94 & 2.82 & 2.00 & 1.39 & 1.76 & 2.53 \\
\hline & 2.01 & 1.67 & 1.09 & 1.31 & 2.07 & 1.48 & 1.35 & 1.89 & 2.11 & 1.48 & 1.16 & 1.65 \\
\hline \multirow[t]{6}{*}{320} & 2.05 & 1.22 & 4.53 & 7.59 & 2.04 & 1.07 & 3.35 & 6.39 & 2.06 & 1.21 & 3.26 & 5.55 \\
\hline & 2.00 & 1.35 & 3.88 & 5.76 & 2.07 & 1.22 & 3.32 & 5.63 & 2.03 & 1.25 & 3.22 & 5.25 \\
\hline & 1.92 & 1.32 & 3.65 & 5.32 & 2.07 & 1.21 & 2.95 & 5.07 & 2.07 & 1.23 & 2.72 & 4.58 \\
\hline & 1.96 & 1.20 & 2.62 & 4.26 & 2.09 & 1.26 & 2.14 & 3.56 & 2.05 & 1.30 & 1.89 & 3.00 \\
\hline & 2.13 & 1.27 & 1.79 & 3.01 & 2.21 & 1.27 & 1.64 & 2.84 & 2.13 & 1.35 & 1.55 & 2.46 \\
\hline & 2.25 & 1.26 & 1.17 & 2.08 & 2.23 & 1.40 & 1.16 & 1.85 & 2.13 & 1.45 & 1.09 & 1.59 \\
\hline
\end{tabular}

${ }^{a}$ By limiting viscosity number measurements. ${ }^{b}$ Oligomers before hydrogenation prepared by thermal degradation of polyisobutyne $\left(M_{n 0}=2.50 \times 10^{5}\right) . \quad{ }^{c}$ Oligomers after hydrogenation of the thermally prepared oligomer $\left(M_{n 0}=7.09 \times 10^{3}\right)$.

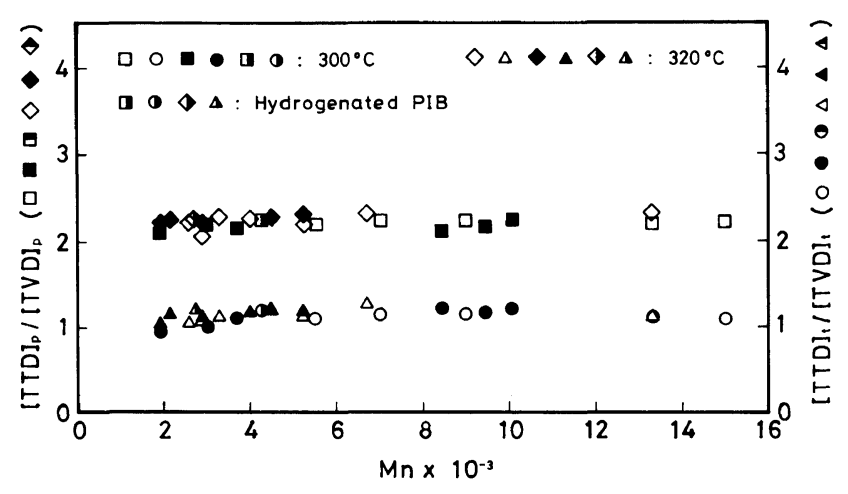

Figure 2. Plot of $M_{n}$ of the nonvolatile oligomers $v s$. the composition ratios $\left([T T D]_{\mathrm{p}} /[\mathrm{TVD}]_{\mathrm{p}}\right.$ and $\left.[\mathrm{TTD}]_{\mathrm{t}} /[\mathrm{TVD}]_{\mathrm{t}}\right)$ in trimers for various initial molecular weights $(\square, \boldsymbol{\square}, \boldsymbol{\square}, \diamond, \mathbf{\Delta}, \triangleleft, \Delta)$ as well as reaction times $(\square, \bigcirc, \diamond, \triangle) .^{2 b}$

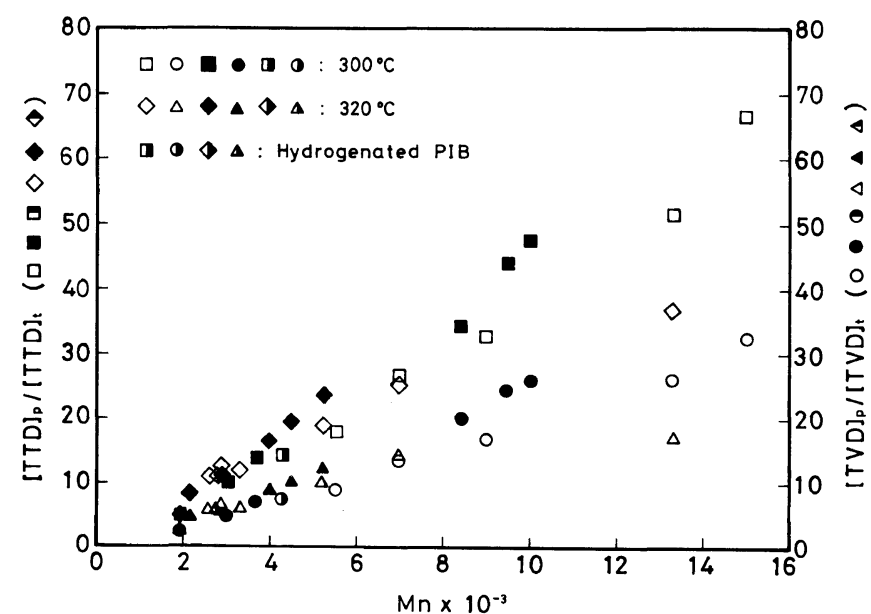

Figure 3. Plot of $M_{n}$ of the nonvolatile oligomers $v s$. the composition ratios $\left([T T D]_{\mathrm{p}} /[\mathrm{TTD}]_{\mathrm{t}}\right.$ and $\left.[\text { TVD }]_{\mathrm{p}} /[\mathrm{TVD}]_{\mathrm{t}}\right)$ in trimers for various initial molecular weights $(\boldsymbol{\square}, \boldsymbol{\odot}, \boldsymbol{\square}, \boldsymbol{\bullet}, \triangleleft, \mathbf{\Delta}, \triangleleft, \boldsymbol{\Delta})$ as well as reaction times $(\square, \bigcirc, \diamond, \triangle) .^{2 b}$ 
Table V. $M_{n}$ Dependence of composition ratios for respective oligomer of interest in the volatile oligomers by thermal degradation of polyisobutylene $\left(M_{n 0}=2.50 \times 10^{5}\right)$

\begin{tabular}{|c|c|c|c|c|c|c|c|c|c|c|c|c|}
\hline \multirow{3}{*}{$\frac{\text { Temp }}{{ }^{\circ} \mathrm{C}}$} & \multirow{3}{*}{ Contents } & \multicolumn{2}{|c|}{ Trimers } & \multicolumn{2}{|c|}{ Tetramers } & \multicolumn{2}{|c|}{ Pentamers } & \multicolumn{2}{|c|}{ Hexamers } & \multicolumn{2}{|c|}{ Heptamers } & \multirow{3}{*}{ Average } \\
\hline & & {$[\mathrm{TTD}]_{\mathrm{p}}$} & {$[\text { TVD }]_{p}$} & {$\left[\mathrm{TTD}_{\mathrm{p}}\right.$} & {$\left[\mathrm{TVD}_{\mathrm{p}}\right.$} & {$[\mathrm{TTD}]_{\mathrm{p}}$} & {$[\mathrm{TVD}]_{\mathrm{p}}$} & {$[\text { TTD }]_{p}$} & {$[\mathrm{TVD}]_{\mathrm{p}}$} & {$[\mathrm{TTD}]_{\mathrm{p}}$} & {$[\mathrm{TVD}]_{\mathrm{p}}$} & \\
\hline & & {$[\mathrm{TTD}]_{\mathrm{t}}$} & {$\left[\mathrm{TVD}_{\mathrm{t}}\right.$} & {$[\mathrm{TTD}]_{\mathrm{t}}$} & {$[\text { TVD }]_{\mathrm{t}}$} & {$[\mathrm{TTD}]_{\mathrm{t}}$} & {$[\mathrm{TVD}]_{\mathrm{t}}$} & {$[\mathrm{TTD}]_{\mathfrak{t}}$} & {$[\text { TVD }]_{\mathrm{t}}$} & {$[\mathrm{TTD}]_{\mathrm{t}}$} & {$[\text { TVD }]_{\mathrm{t}}$} & \\
\hline \multirow[t]{2}{*}{300} & $\begin{array}{l}\text { Coefficient of } \\
\text { correlation }\end{array}$ & 0.96 & 0.92 & 0.99 & 0.94 & 0.97 & 0.99 & 0.98 & 0.90 & 0.92 & 0.93 & \\
\hline & $2 a$ Value & 2.20 & 2.40 & 1.96 & 1.84 & 2.22 & 2.00 & 2.02 & 1.88 & 2.22 & 1.96 & 2.07 \\
\hline \multirow[t]{2}{*}{320} & $\begin{array}{c}\text { Coefficient of } \\
\text { correlation }\end{array}$ & 0.96 & 0.95 & 0.99 & 0.99 & 0.99 & 0.97 & 0.98 & 0.94 & 0.99 & 0.97 & \\
\hline & $2 a$ Value & 1.78 & 1.98 & 1.62 & 1.96 & 1.68 & 1.80 & 1.68 & 1.84 & 2.00 & 1.86 & 1.79 \\
\hline
\end{tabular}

2, and slightly higher at $300^{\circ} \mathrm{C}(c a .2 .1)$ than that at $320^{\circ} \mathrm{C}(\mathrm{ca} .1 .8)$. The value is nearly constant for every oligomer at the same temperature. This verifies that back-biting depends on the chain conformations around the chain end radical. ${ }^{2 b}$

\section{Effects of Initiation on Radical Concentration}

The end initiation ${ }^{1 b}$ at the thermally labile bonds of allylic position from the terminal double bond is of importance in addition to the random initiation by scission of the skeletal $\mathrm{C}-\mathrm{C}$ bond. ${ }^{3}$ As degradation proceeds, the initiation rate of degradation increases with decrease in the molecular weight because of increment of concentration of terminal double bond. As wellknown, ${ }^{2-4}$ both $R_{p}$ and $R_{t} \cdot$ formed in the random and/or end initiation ${ }^{1 b}$ regenerate frequently $R_{p}$. by elementary reactions in the depropagation step. Consequently, the stationary concentration of $R_{p} \cdot$ should be much higher than that of $\mathrm{R}_{\mathrm{t}} \cdot{ }^{1 \mathrm{~b}}$ For this reason, the increase of initiation rate should result in increase in radical concentration and thereby may increase the ratios of eq 3 and 4 through increment of the rate of formation of $R_{p}$. in the depropagation step. Namely, the absence of TVD and TTD on the hydrogenated samples decreases the concentrations $\left[R_{p} \cdot\right]$ and $\left[R_{t} \cdot\right]$ and the rates of elementary reactions in the depropagation step. A sample of hydrogenated polyisobutylene $\left(M_{n 0}=\right.$ $7.09 \times 10^{3}$ ) was used to examine the effects of TVD and TTD.

For the hydrogenated polyisobutylene (Table IV and Figure 2), effects of hydrogenation were found only at $300^{\circ} \mathrm{C}$, where $M_{n}$ value increased and volatilization decreased by hydrogenation. Any noticeable change in all the ratios is not found at $320^{\circ} \mathrm{C}$, probably owing to increase in the random initiation in addition to end initiation. At $300^{\circ} \mathrm{C}$ the ratios $[\text { TTD }]_{\mathrm{p}} /[\mathrm{TTD}]_{\mathrm{t}}$ and $[T V D]_{\mathrm{p}} /[\mathrm{TVD}]_{\mathrm{t}}$ become slightly higher after hydrogenation. The decrease in end initiation rate by hydrogenation results in decrement of $\left[R_{p} \cdot\right]$ and $\left[R_{t} \cdot\right]$. However, the concentration ratio $\left[R_{p} \cdot\right] /\left[R_{t} \cdot\right]$ does not decrease as expected above but increases. Consequently, we should note that the marked changes in the stationary concentrations of $R_{p}$. and $R_{t}$. would be caused by increase of the disappearance rate by termination reactions rather than formation rate of radicals by initiation with decreasing $M_{n}$ during degradation.

\section{Effects of Termination on Radical Concentration}

The effects of molecular weight on the concentrations of $R_{p} \cdot$ and $R_{t} \cdot$ during the degradation would be exactly evaluated through analysis of molecular weight dependence of the elementary reactions in the radical degradation mechanism. For the thermal degradation of anionically prepared polystyrene in the melt, it was reported $^{7}$ that the rate of random scission increases with initial molecular weight of sample and this was explained as due to increase in macroradical concentration based on the mechanism including diffusion-controlled termination reactions. ${ }^{1 \mathrm{a}}$ The decrease in the concentration ratio $\left[R_{p} \cdot\right] /\left[R_{t} \cdot\right]$ during degradation is also explained by this mechanism. As described above, $R_{p}$. and $R_{t}$. formed by the initiations participate in the degradation process to form newly $R_{p}$. in the depropagation step. The stationary concentrations of $R_{p} \cdot$ and $R_{t} \cdot$ are dependent on the differences in rates of radical formation and disappearance. Therefore, the rate of reformation of $R_{p}$. in the depropagation step is mainly regulated through changes in the radical concentrations by unbalance between the rates of initiation and termination. This concept could be supported by a larger molecular weight dependence of the rate of termination than that of the initiation rate.

\section{Reaction Model}

In eq 3 and 4 , the molecular weight dependence of $\left[R_{p} \cdot\right]$ and $\left[R_{t} \cdot\right]$ differs and should be separately analyzed. In the present study, however, only the formation of the volatile oligomers was measured for the backbiting reactions of $R_{p} \cdot$ and $R_{t} \cdot$. Other products such as the nonvolatile oligomers and isobutylene monomer are also formed via elementary reactions of $R_{p} \cdot$ and $R_{t} \cdot{ }^{2-4}$ As described above, the concentration $\left[\mathrm{R}_{\mathrm{p}} \cdot\right]$ would largely decrease than $\left[\mathrm{R}_{\mathrm{t}}{ }^{\cdot}\right]$ with decreasing $M_{n}$ during degradation. Here, we interpret the results (Table V) of the molecular weight dependency of eq 6 using a simpler reaction model based on the chain mechanism, in which the two terminal macroradicals $R_{p} \cdot$ and $R_{t} \cdot$ are not discriminated from one another but treated as only one terminal macroradical $\mathrm{R}$.

The total reaction consists of the following steps.

Initiation

(End initiation)

$$
\mathrm{PU} \stackrel{k_{\mathrm{ie}}}{\longrightarrow} \mathrm{R} \cdot+\mathrm{S}
$$


(Random initiation)

$$
\mathrm{P} \stackrel{k_{\mathrm{ir}}}{\longrightarrow} 2 \mathrm{R} \text {. }
$$

\section{Depropagation}

(Depolymerization, viz., direct $\beta$ scission)

$$
\mathrm{R} \cdot \stackrel{k_{\mathrm{d}}}{\longrightarrow} \mathrm{m}+\mathrm{R} \text {. }
$$

(Back-biting followed by $\beta$ scission)

$$
\begin{gathered}
\mathrm{R} \cdot \stackrel{k_{\mathrm{b}}}{\longrightarrow} \mathrm{R}_{\mathrm{ob}} . \\
\mathrm{R}_{\mathrm{ob}} \cdot \stackrel{k_{\mathrm{sb}}}{\longrightarrow} \mathrm{O}+\mathrm{R} .
\end{gathered}
$$

(Intermolecular hydrogen abstraction followed by $\beta$ scission)

$$
\begin{gathered}
\mathrm{R} \cdot+\mathrm{P} \stackrel{k_{\mathrm{r}}}{\longrightarrow} \mathrm{PS}+\mathrm{R}_{\mathrm{or}} \\
\mathrm{R}_{\mathrm{or}} \cdot \stackrel{k_{\mathrm{sr}}}{\longrightarrow} \mathrm{PU}+\mathrm{R} .
\end{gathered}
$$

\section{Bimolecular Termination}

(Disproportionation)

$$
2 \mathrm{R} \cdot \stackrel{k_{\mathrm{td}}}{\longrightarrow} \mathrm{PS}+\mathrm{PU}
$$

(Recombination)

$$
2 \mathrm{R} \cdot \stackrel{k_{\mathrm{tc}}}{\longrightarrow} \mathrm{P}
$$

where, $\mathrm{P}$, polymer including PU and PS; PU, polymer having an unsaturated end group; PS, polymer having a saturated end group; R ·, terminal macroradical; $\mathrm{S} \cdot$, volatile small radical; $\mathrm{R}_{\mathrm{ob}} \cdot$, on-chain macroradical which has unpaired electron in vicinity of the chain end; $R_{\text {or }}$, on-chain macroradical which has unpaired electron at random position of the main chain; $\mathrm{m}$, monomer; o, volatile oligomers.

\section{Kinetics Based on Activation-Controlled Termination}

The rate of end initiation (eq 7) depends on [PU] which is equal to $f[\mathrm{P}],{ }^{8}$ where $f$ is the number of terminal double bonds per molecule. [P] is expressed by $\rho / M$, where $\rho$ and $M$ are the density and molecular weight of polymer, respectively. Random initiation occurs at any position of the main chain and, therefore, [P] should be replaced by the concentration [N] of monomer unit in the polymer. [N] is expressed by $\rho / m,{ }^{8}$ where $m$ is the molecular weight of monomer unit. From this, the value of $[\mathrm{N}]$ could be set nearly constant during the degradation, because the specific volume $\left(v_{\mathrm{sp}}\right)$ of polyisobutylene having a molecular weight ranging from 3540 to 115000 at $217^{\circ} \mathrm{C}$ is nearly constant, as shown by the equation ${ }^{9}: v_{\mathrm{sp}}=1.225+32 / M$. Under these conditions, the rate equations of the reactions 7,8 , and 12 are expressed as follows,

$$
\begin{aligned}
& V_{\mathrm{ie}}=k_{\mathrm{ie}} f \rho M^{-1} \\
& V_{\mathrm{ir}}=k_{\mathrm{ir}}[\mathrm{N}] \\
& V_{\mathrm{r}}=k_{\mathrm{r}}[\mathrm{R} \cdot][\mathrm{N}]
\end{aligned}
$$

Thus, the rate of end initiation is inversely proportional to $M$, and the rate of random initiation remains constant. On the other hand, the rate of intermolecular hydrogen abstraction depends only on $[\mathrm{R} \cdot]$. It was verified in the preceding paper, ${ }^{2 \mathrm{~b}}$ that reactions 10 and 11 occur under steady state conditions where concentration $\left[R_{\mathrm{ob}} \cdot\right]$ is kept low and constant and, therefrom, these reactions could be represented only by the rate equation of the back-biting (eq 10). Similarly, the rate equations of reactions 12 and 13 could be represented only by eq 12 . Assuming that degradation reactions proceed under steady state conditions regarding $[\mathrm{R} \cdot]$, the following relationship holds;

$$
\begin{aligned}
\frac{\mathrm{d}[\mathrm{R} \cdot]}{\mathrm{d} t}= & V_{\mathrm{ie}}+2 V_{\mathrm{ir}}+V_{\mathrm{d}}+V_{\mathrm{b}}+V_{\mathrm{r}} \\
& -V_{\mathrm{d}}-V_{\mathrm{b}}-V_{\mathrm{r}}-2 V_{\mathrm{td}}-2 V_{\mathrm{tc}}=0
\end{aligned}
$$

From this relationship, $[\mathrm{R} \cdot]^{2}$ is expressed by

$$
[\mathrm{R} \cdot]^{2}=\frac{k_{\mathrm{ie}} f \rho M^{-1}}{2 k_{\mathrm{t}}}+\frac{k_{\mathrm{ir}}[\mathrm{N}]}{k_{\mathrm{t}}}
$$

where, $k_{\mathrm{t}}=k_{\mathrm{td}}+k_{\mathrm{tc}}$

As shown in eq $20,[\mathrm{R} \cdot]^{2}$ is linearly proportional to $M^{-1}$ during degradation, according to the chain mechanism with activation-controlled termination independent of the molecular weight of matrix. This means increase in radical concentration as the reaction proceeds, which is inconsistent with the experimental data.

\section{Kinetics Based on Diffusion-Controlled Termination}

If the rate of bimolecular termination (eq 14 and 15) is controlled by diffusional motion of $\mathrm{R} \cdot$, the rate constant $k_{\mathrm{t}}$ is governed by the frequency of encounter of two macroradicals ${ }^{10}$ and, therefore, the diffusion coefficient $D_{\mathrm{s}}$ of macroradical, is related to some power of molecular weight; that is,

$$
k_{\mathrm{t}}=4 \pi R D N_{\mathrm{A}}=K_{\mathrm{t}} M^{-b}
$$

where, $R$, radius of reaction sphere; $D$, sum of diffusion coefficients of two reacting molecules; $N_{\mathrm{A}}$, Avogadro constant; $K_{\mathrm{t}}$, a parameter; $D_{\mathrm{s}}$, diffusion coefficient of $\mathrm{R}$. $\left(\propto M^{-b}\right)$.

In this case, eq 20 is represented as a function of $M$ as follows,

$$
[\mathrm{R} \cdot]^{2}=\left(\frac{k_{\mathrm{ie}} f \rho}{2 K_{\mathrm{t}}}\right) M^{(-1+b)}+\left(\frac{k_{\mathrm{ir}}[\mathrm{N}]}{K_{\mathrm{t}}}\right) M^{b}
$$

The first term of the right hand of eq 22 is related to the end initiation (eq 7), and molecular weight dependence is given by the exponent $(-1+b)$. The second term concerns the random initiation (eq 8) and its molecular weight dependence $M^{b}$ comes from the termination (eq 14 and 15). Owing to this, the molecular weight dependence of $[\mathrm{R} \cdot]^{2}$ should gradually change with the molecular weight of the matrix during the degradation. If the effective motion of the reacting end of macroradical in the molten polymer matrix is mainly controlled by self-diffusion, the exponent $b$ is equal to $c a .2 .{ }^{11}$ In this case, the power of molecular weight dependence of $[\mathrm{R} \cdot]^{2}$ would vary in a range from 1 to 2 during the degradation.

The relationship given by eq 6 is compared with that of eq 22. The trend in molecular weight dependencies of the ratio of $\left[R_{p} \cdot\right]$ and $\left[R_{t} \cdot\right]$ shown in Table $V$ is 
roughly consistent with the kinetic expectation of eq 22 , in which the power of the molecular weight dependence of $[\mathrm{R} \cdot]^{2}$ vary in a range from 1 to 2 assuming $2^{11}$ for the value of $b$. Moreover, the observed value of exponent $2 a$ suggests that the random initiation occurs predominantly than the end initiation and supports that the radical concentration ratio $\left[\mathrm{R}_{\mathrm{p}} \cdot\right] /\left[\mathrm{R}_{\mathrm{t}} \cdot\right]$ is independent of the end initiation. This result makes clear that the rate of termination depends on the diffusional process of reacting radicals in the molten polymer matrix. Namely, the rate constant of termination increases with a decreasing molecular weight of the matrix, and the resulting decrease in radical concentration causes a decrement of rate of elementary reactions giving $R \cdot\left(R_{p} \cdot\right)$ in the depropagation step.

\section{Change in Kinetic Chain Length}

According to the simple mechanism described above, a kinetic chain length (KCL) is given as follows,

$$
\mathrm{KCL}=\frac{V_{\mathrm{d}}+V_{\mathrm{b}}+V_{\mathrm{r}}}{V_{\mathrm{t}}}=\frac{k_{\mathrm{d}}+k_{\mathrm{b}}+k_{\mathrm{r}}[\mathrm{N}]}{k_{\mathrm{t}}[\mathrm{R} \cdot]}
$$

When eq 23 is substituted in eq 21 and 22 ,

$$
(\mathrm{KCL})^{2} \propto \frac{M^{(1+2 b)}}{M^{(1+b)}+M^{b}}
$$

Assuming 2 for the value of $b$ in eq $24,{ }^{11}$ the value of $(\mathrm{KCL})^{2}$ is expected to decrease remarkably with decrease in $M$ during degradation. Therefore, a marked decrement of the radical concentration ratio suggests that the rate of termination increases with decrease in molecular weight of the matrix and that a resulting larger decrement of KCL depresses the formation of primary terminal macroradical $\left(\mathrm{R}_{\mathrm{p}} \cdot\right)$ in the depropagation step.

In this paper, only the behavior of volatile oligomers is discussed. The validity of the proposed mechanism including diffusion-controlled termination should be checked for the composition ratios of other products obtained in the experiment. We will report the results obtained by examining structural changes of the nonvolatile oligomers, and then simulate all the processes of thermal degradation of polyisobutylene by the reaction model based on a free-radical chain mechanism with diffusion-controlled termination in a subsequent paper.

\section{CONCLUSIONS}

The thermal degradation of polyisobutylene was clarified to be affected by the molecular weight of molten polymers constituting reaction media. A characteristic feature is decrease in the radical concentration with decreasing molecular weight, presumably owing to increase in the rate of diffusion-controlled bimolecular termination. Moreover, it is noteworthy that the backbiting is a uni-molecular type reaction, and its rate depends only on the chain conformation in the vicinity of the reacting end, is independent of the molecular weight or chain length of the reacting molecules.

\section{REFERENCES}

1. (a) I. Mita and K. Horie,"Degradation and Stabilization of Polymers-1," H. H. G. Jellinek, Ed., Elsevier, New York, N.Y., 1983, p 235. (b) I. Mita, "Aspects of Degradation and Stabilization of Polymers," H. H. G. Jellinek, Ed., Elsevir, New York, N.Y., 1978, p 247.

2. (a) T. Sawaguchi, T. Takesue, T. Ikemura, and M. Seno, Macromol. Chem. Phys., 196, 4139 (1995). (b) T. Sawaguchi, T. Ikemura, and M. Seno, Macromol. Chem. Phys., 197, 215 (1996).

3. Y. Tsuchiya and K. Sumi, J. Polym. Sci., A-1, 7, 813 (1969).

4. T. Kuroki, T, Sawaguchi, K. Suzuki, S. Ide, and T. Ikemura, Polymer, 24, 428 (1983).

5. Y. Sakaguchi and I. Sakurada, Koubunshi Kagaku, 5, 242 (1948).

6. V. Srinivasan and S. V. Babu, Polym. J., 17, 525 (1985).

7. G. G. Cameron and G. P. Kerr, Eur. Polym. J., 4, 709 (1968).

8. (a) G. G. Cameron, Makromol. Chem., 100, 255 (1967). (b) G. G. Cameron J. M. Meyer, and I. T. McWalter, Macromolecules, 11, 696 (1978).

9. T. G. Fox and P. J. Flory, J. Phys. Colloid Chem., 55, 221 (1951).

10. M. Smoluchowski, Z. Phys. Chem., 92, 129 (1918).

11. P. G. de Gennes, "Scaling Concepts in Polymer Physics," Cornell University Press, New York, N.Y., 1979. 